\title{
ASCERTAINING THE USE OF EXTRACURRICULAR ACTIVITIES IN PROMOTING LEARNERS' HOLISTIC DEVELOPMENT IN MULTICULTURAL SCHOOL SETTINGS
}

\author{
Gregory Alexander ${ }^{1}$, Sheila Matoti ${ }^{2}$, \& Pieter Van Zyl ${ }^{1}$ \\ ${ }^{1}$ Faculty of Humanities, Central University of Technology (South Africa) \\ ${ }^{2}$ Scholarship of Teaching \& Learning Unit, Central University of Technology (South Africa)
}

\begin{abstract}
Encouraging learners to participate in extracurricular activities should commence in the early phase of their growth where a basis for their personality, learning and development is laid. Extracurricular activities could further assist in improving learners' creativity and artistic talents. Philosophers, such as Rousseau, Spencer and Dewey further reiterate the value of extracurricular activities in developing social relationships and intellectual intelligence. Learners associate with different peer groups which may satisfy their socialisation, self-assessment, self-identification and the fulfilment of their needs in becoming self-actualised. Learners can further be enabled to reach self-actualisation by participating in academic activities, such as maths, science clubs and research projects. Such activities seemingly contribute to learners' academic development which in turn may assist them in mastering certain life tasks; developing leadership roles; increasing their involvement in the community and expressing their civil responsibility. Amidst the latter, it is noted that the lack or in some cases, the non-existence of extracurricular activities hinder learners' growth and learning, especially in multicultural school settings, where the foundation for learners' development has to occur in a conducive environment. Multicultural schools in the Letjweleputswa educational district, Free State province of South Africa seem not to use extracurricular activities as an effective tool in promoting learners' holistic development. The aim of this paper is to ascertain the use of extracurricular activities in promoting learners' holistic development in the Letjweleputswa educational district. Via a qualitative research methodology, three focus group interviews were conducted with 20 learners attached to four multicultural schools. Findings of the study revealed that learner participants are of the view that their involvement in extracurricular activities could give them a greater chance of being employed; of getting a better job; of being accepted into university and of developing certain attributes, such as creativity, innovation, problem solving and endurance. The study further recommends that multicultural schools in the Letjweleputswa educational district need to implement various extracurricular activities as a means of developing various traits and competencies such as learners' physical-, emotional-, cognitive and social skills; moral underpinnings, life-skills, well-being, leadership qualities, analytical thinking processes and communication abilities.
\end{abstract}

Keywords: Extracurricular activities, holistic development, multicultural schools.

\section{Introduction}

Extracurricular activities fulfil a crucial role in school curricula as to allow learners to reveal their hidden potential for development (Krishnamurti, 2003)- it also assists them to improve on their creativity and artistic talents. Learners associate with different peer groups and through this process, they acquire skills with socialisation, self-assessment, self-identification and the fulfilment of their need to become self-actualised. Therefore, we argue that extracurricular activities can contribute to learners' academic development, which later in life may be used to develop leadership roles; increase participation in community initiatives and assist with the empowerment of other citizens (Barge, 2015). Kapur (2015), argues that circumstances in developing countries, such as South Africa, limit human activities in social, economic, cultural and educational development. Lleras (2009) observed that in Illinois high schools in the USA, where learners were exposed to extracurricular activities, they were highly praised by their teachers as having good social skills and work habits. Furthermore, these learners obtained higher levels of education in quicker times, than some of their classmates who participated less in extracurricular activities. Learners' desire to grow can be motivated through the establishment of participation in 
extracurricular activities (Pioner, 2015). In some instances, schools request additional fees and costs from parents as a mechanism of enhancing learners' holistic development- this is fulfilled through various sporting codes, school newspapers, literary activities, drama clubs and cultural clubs. Extracurricular activities need to be managed according to learners' needs and desires and as such ensure an appropriate development structure to ground effective strategies which could possibly be used by teachers. Encouraging learners to participate in extracurricular activities should commence in the early phase of childhood education where the platform for learners' personality, learning and development is laid. Learners come into contact with peers who also engage in extracurricular activities. Therefore, schools should initiate opportunities to advance appropriate strategies as a measure of promoting learners' holistic development, especially in the early phase of their development where learners have to indulged in play (Sampson, 2012). Extracurricular activities assist in improving the creativity and artistic talents of learners. Learners associate with different peer groups, which may satisfy their need for socialisation, self-assessment, self-identification and self-actualisation. Learners can further be enabled to reach self-actualisation by participating in academic activities, such as maths, science clubs and research projects. Such activities contribute to learners' academic growth which in turn may assist them in mastering certain life tasks; developing leadership roles, increasing their involvement in the community and expressing their civil responsibly (Barge, 2015).

According to Thakur (2013), it is an accepted norm that extracurricular activities support learners social and personal development skills. Extracurricular activities generate positive growth in human development. Kapur's (2015) further states that extracurricular activities promote all aspects of human development, regardless of anomalies; even more so in multicultural school environments, where the development of learners as holistic beings, is perceived as cardinal. The holistic view of human development can be observed in different aspects, such as the physical, emotional, mental, spiritual and social. In all, we argue that there is a causal link between participation in extracurricular activities, holistic development and academic performance (Thakur, $2013 \& \&$ Mason, 2017). The vision of the Department of Basic Education in South Arica is pronged in providing conducive learning environments for the enhancement of learners' full potential in all aspects of their holistic growth. Quality care and education as set out by the Department of Education in South Africa during early childhood, is valuable to children's growth and development throughout their lives. The benefits identified by Dlamini (2017), such as physical development (use of sports develop good motor skills);emotional development (learners learn to cope with a wider range of scenarios, such as compassion and empathy); communication skills (learners learn to communicate with a knowledgeable other); cognitive development (give learners opportunity to express creativity); creative development (may develop enthusiastic approach to learning); healthy learning (exercises, activities and games make learners aware of their surroundings); and special awareness (changing learners' developing brains, acquiring skills, such as problem-solving and arithmetic) are cardinal to human development. These are some aspects that could possibly contribute to the holistic development of learners.

\section{Theoretical framework}

The study will be grounded in Urie Bronfenbrenner's bio-ecological model. This model proposes that a person's growth might be influenced by a set of systems in their environment such as family, peers and social institutions, such as school or extracurricular activities (Eggen \& Kauchak, 2014). A learner's growth could be influenced by a set of systems in their environment, such as family, peers and social institutions, schools and exposure/non exposure to extracurricular activities (Eggen \& Kauchak 2014). The surroundings and realities that learners engage with family, peers, teachers and coaches might provide ideal resources and assets for aspects of learners' holistic development (cognitive, emotional, social, spiritual, academic and physical). The visibility of social realities prevalent in Bronfenbrenner's theory, might be absent in the lives of most learners residing in the Letjweleputswa educational district. If teachers have knowledge of the systems and the effect they have on the development of their learners, they may assist learners to develop in relation to their age, ability difference, contextual background and diversity.

\section{Aim of the paper}

The aim of this paper is to ascertain the use of extracurricular activities in promoting learners' holistic development in the Letjweleputswa educational district of the Free State province, South Africa. 


\section{Statement of the problem}

Statistics South Africa (2016), indicate that there is a large percentage of learners in Brandfort schools, Letjweleputswa educational district who experience challenges in completing their schooling. A total of 367 out of 3134 people obtained higher education, while 1065 out of 3134 people completed their grade 12 school leaving certificate. Learners are exposed to various challenges and poor socio-economic conditions. We (authors of paper) also observed that the lack or in some cases, the non-existence of extracurricular activities hinder aspects confined to learners' holistic growth needs, especially in multicultural school settings, where the base for learners' development has to occur in a conducive environment. Multicultural schools in the Letjweleputswa educational district of the Free State province seem not to use extracurricular activities as an effective tool in promoting learners' holistic development. Numerous conditions also seem to contribute to this situation. Teachers lack the knowledge and skills in developing learners optimally and granting them fair opportunities in reaching their full potential, appear also to be a contributing factor in delimiting learners' holistic development. Therefore, the main question guiding this paper is: What do learners think of the use of extracurricular activities in promoting their holistic development?

\section{Research methodology}

A qualitative research approach was pursued in realising, the aim for this study. Learners' views and lived experiences on the use of extracurricular activities in promoting their holistic development was investigated via semi- structured focus group interviews. Qualitative research may refer to research about behaviours, emotions, people's lives, lived experiences and cultural phenomena. According to Eggen and Kauchak's (2014), Bronfenbrenner's bio-ecological systems approach, benefits the use of qualitative approach, purely by the fact that through this approach, data can be gathered to ascertain research participants behaviours, emotions, lived experiences, cultural values and beliefs. From a total of 39 learners from 6 schools who participated in the study, the views and experiences of 20 learners (4 focus groups) attached to four multicultural schools, are only used for reporting in this short paper. The focus group interviews were held with a diverse group of learners who participated in extracurricular and cultural activities. A thematic analysis a was used to interpret data emerging from the focus group interviews.

\section{Analysis and discussion of findings}

For the sake of this short paper, the authors have opted to discuss the findings of the most prominent themes, emerging from the data. For example, the code FGA L1 means Focus Group of School A \& Learner Participant 1.

\subsection{Theme 1: Benefits of various sporting codes}

The authors wanted to get an idea of the extracurricular activities being offered at multicultural schools. Participants (FGA L1, FGA L5, FGA L6, FGB L2, FGB L6, FGD L4, and FGD L5) indicated that their schools offer sport, but were not specific in the sport codes offered. Sport can be defined as an organised, competitive and skilful activity which necessitate dedication and fair play. Participants indicated that their schools offer sports in the form of athletics, netball, cricket, rugby, soccer, swimming, tennis, and horse riding. Some participants expressed their views as follow:

FGB L6: "Sport: athletics, netball, rugby, cricket, swimming, tennis, and horse riding." $\boldsymbol{F G} \boldsymbol{A}$ L3: "My school offers learners the opportunity to participate in horse riding as an extracurricular activity outside the formal school day activities." FGF L6: "My school offers indigenous games as an extracurricular activity. Indigenous games such as Morabaraba and Draft."

It should be noted that the various multicultural schools offer different sport codes- this is also dependent on whether the respective school is well-or under resourced (human, physical and financial resources; adequate infrastructure and facilities). Participating in sport means using time designated for physical, healthy and mental activity that refreshes the human body and as such, yields certain benefits to learners (Steinberg, 2018).

\subsection{Theme 2: Personal acceptance for participation in extracurricular activities}

The authors wanted to get a sense of the specific extracurricular activities (sport, art, choir, drama, indigenous games, library and reading club, cultural events, community service outreach, etc.) learners participate in and the reasons for their choice. Participants (FGA L1 and FGA L4) stated that 
they are involved in extracurricular activities because of the teacher who coaches, encourages, and motivates them as individuals. The role of coaches is often performed by a range of general education and special education teachers with expertise in instructional practices, with school psychologists, often assuming the role of a school coach (Snyder, Hemmeter \& Fox, 2015).

FGA L4: "We are one of the best rural schools when it comes to playing rugby, and the coaches are the ones motivating us." FGB L3: "I participate to get my mind off things and to develop my self-confidence to be able to work in groups." FGA L5: "I participate in the reading club because reading is my favourite activity and I enjoy it." $\boldsymbol{F G B}$ L3: "It increases my abilities and self-esteem to work in a group, interacting with others and also being able to listen to others increases my self-esteem."

Extracurricular activities in multicultural school settings seem to assist learners in strengthening their emotional abilities; develop their social interaction amongst peers; and build their self-confidence. Extracurricular activities promote social and emotional development which is critical in developing learners' ability to develop relationships; be self-confident; trust others; and manage diversity and stress in a healthy way (Wilson, 2009).

\subsection{Theme 3: Value of extra-mural activities with learners' holistic development}

The authors pronged learner participants to indicate how they using extramural activities in assisting with an aspect of their development (academics, physical, social, emotional, spiritual etc.) or with their motivation. Participants (FGB L5, FGB L6, FGB L7, FGD L9, FGC L5, FGC L6, FGD L3) mentioned that the teachers motivate and encourage them to do better in academic activities and also to be more involved during lessons. It is essential for teachers to motivate learners and assist them in identifying their strengths and weaknesses (Shava, 2016). The following sentiments were articulated by some learner participants.

FGB L9 "The teachers are using these activities to assist with academic work and also encouraging me to not think the worst of myself but be positive all the time because positive thoughts create positive achievements." FGC L2: "The teacher has helped me develop physically as well as emotionally; to pressure me in a positive way to be the best player I can be in netball." FGD L5: "Both my teachers motivate me to be more sociable with my peers/friends and that is why I participate in extracurricular activities and am happy when I do so."

From the above said, it appears that teachers motivate learners to be involved in sport and cultural activities which assist with aspects of their holistic development. Sport codes which are played in a team format enhances socialisation amongst peer and friendship groups. It further appears as though teachers motivate learners to participate in extra mural activities, especially to enhance learners' self-esteem, confidence and to motivate them academically, socially and spiritually. Spiritual development is the growth of the non-material aspects of life, concentrating on personal insight, values, meanings and purpose (Roundy, 2018).

\section{Conclusion}

Learner participants stated that their involvement in extracurricular activities in multicultural schools could also give them a greater chance of being employed; of getting a better job one day; of being accepted into university and of developing certain attributes, such as creativity, innovation, and endurance. The study recommends that multicultural schools in the Letjweleputswa educational district need to implement various extracurricular activities as to develop a range of traits and competencies for their learners- this response of schools could possible cultivate an institutional atmosphere for the development of learners' physical, emotional, cognitive, social, moral underpinnings, problem-solving, academic, life-skills, well-being, leadership skills, analytical skills, and communication skills. Furthermore, extracurricular activities in multicultural schools can increase a learner's social support system, develop social skills and good relationships, which in turn could enhance cohesion amongst learners (Freeman, 2017). Learners who participate in extracurricular activities also develop invaluable competencies required for the forging of good relationships, such as having an inclination to isolate themselves from peers/friends who use alcohol and drugs. Moreover, learners learn a sense of accountability, fair play and morality which inspires them to build positive awareness in peer relationships. 


\section{References}

Barge, M.A. (2015). Complete List of Extracurricular Activities: 100s Examples. [Blog post]. Retrieved from http://blog.prepscholar.com/list-of-extracurricular-activities-examples [Accessed on 3 June 2019].

Dlamini, K. (2017) The significant benefits of early childhood development. [Blog post]. Retrieved from Damelin correspondence: https://www.dcc.edu.za/latest-news/the-significant-benefits-of-earlychildhood-development. [Accessed on 31 October 2019].

Eggen, P. \& Kauchak, D. (2014). Personal, Social, and Moral development. In Eggen, P. \& Kauchak, D. (Limited), Educational Psychology Windows on Classrooms (pp. 79-80). Edinburgh Gate, England: Pearson.

Kapur, R. (2015). Approaches and strategies for holistic social development. Arts and Social Sciences Journal, 6(3): 1-5.

Krishnamurti, J. (2003). Links for visitors unfamiliar with holistic education. Holistic Education. [Blog post]. Retrieved from http://holisticeducation.net/visitors.htm. [Accessed on 16 November 2019].

Mason, D. (2017). Prospects. The importance of extra-curricular activities. [BLog post]. Retrieved from https://www.prospects.ac.uk/careers-advice/applying-for-jobs/the-importance-of-extra-curricularactivities. [Accessed on 17 June 2019].

Poiner, J. (2015). The opportunity gap. Extracurriculars and field trips aren't just for fun. [Blog post]. Retrieved from: https://edexcellence.net/articles/the-opportunity-gap-extracurriculars-and-fieldtrips-aren $\%$ E2\%80\%99t-just-for-fun. [Accessed on 3 November 2019]

Roundy, L. (2018). Physical, social and emotional benefits of participating in sports. [Blog post]. Retrieved from https://study.com/academy/lesson/physical-social-and-emotional-benefits-ofparticipating-in-sports.html. [Accessed on 7 November 2019]

Shava, G.N. (2016). Enhancing learner achievement through professional development. South African Journal of Higher Education, 30(6): 56-72.

Snyder, P.A., Hemmeter, M.L., \& Fox, L. 2015. Supporting implementation of evidence-based practices through practice-based coaching. Topics in early childhood special education, 35(3): 133-143.

Steinberg, L. (2018) What defines a "sport"? [Blog post]. Retrieved from https://www.forbes.com/sites/leighsteinberg/2018/07/28/what-definessport4ac723cf2d6 [Accessed on 27 October 2019].

Thakur, A. (2013). Top 10 benefits of extracurricular activities. [Blog post]. Retrieved from http://topyaps.com/top-10-benefits-of-extracurricular-activities. [Accessed on 9 January 2019].

Wilson, N.L. (2009). Impact of extracurricular activities on students. [Unpublished Master's thesis]. University of Wisconsin-Stout. 